\title{
Elytral surface structure in Poecilus lepidus (Coleoptera: Carabidae): What about the nature of its inheritance?
}

\author{
DIETRICH MOSSAKOWSKI ${ }^{1}$ and WILFRIED PAARMANN ${ }^{2}$
}

\author{
${ }^{1}$ Seeweg 10, D-23942 Groß Schwansee, Germany; e-mail: dmossa@uni-bremen.de \\ ${ }^{2}$ Meenser Weg 9, D-37124 Rosdorf, Atzenhausen, Germany; e-mail: w-paar@t-online.de
}

\begin{abstract}
Key words. Coleoptera, Carabidae, matt and bright elytral surface, colour impression, epigenetics, sex-limited inheritance,
\end{abstract} geographical differences

\begin{abstract}
The cuticle of the ground beetle Poecilus lepidus (Leske) (Coleoptera: Carabidae) displays a complex variety of colour morphs that are genetically determined. Besides the colour of the elytra, there is a remarkable intersexual dimorphic difference in its surface structure between males and females, as there is in most Poecilus species. At least in Central European populations of $P$. lepidus, all males exhibit a bright elytral surface, whereas all females exhibit a matt surface; this difference is due to a nearly plain surface in males but a knobbly sculptured one in females. At first glance, this phenomenon may be easily interpreted as being a result of secondary sexual character inheritance. However, P. lepidus specimens are known from two other regions that differ markedly: females display the same bright elytral surfaces as males in the Italian Apennine Mountain and all over Bulgaria. In the present study, crossbreeding experiments with German and Bulgarian specimens resulted in a dominance of matt over bright in the classical Mendelian $\mathrm{F}_{2}$ $3: 1$ ratio, although only in females. All the males showed a bright elytral surface. These findings throw into question the interpretation as given above. Because classical modes of inheritance do not provide a sound interpretation of the data as here detailed, we discuss two forms of epigenetic mechanisms which might be responsible for the observed sexual dimorphism: (1) silencing of a gene by genomic imprinting, and (2) haplo-insufficient dominance of one allele to its counterpart. Ultimately, the observed pattern is interpreted by sexlimited inheritance that depends on the presence or absence of a particular allele.
\end{abstract}

\section{INTRODUCTION}

The impression of a structural colour as perceived when observing an insect cuticle depends on both the multiple transparent layers within the cuticle as well as the structure of the cuticular surface. Like other insects, many beetles display bright metallic colours due to the presence of multilayer systems. This term covers two modes of colourproducing layers: (i) due to a stack of alternating layers of different refractive indices (and thickness) with a wide range in the numbers of such double layers (quarter wavelength plates); and (ii) a helicoidal order of cholesteric liquid crystals within the layer in which the orientation of chitin micelles rotates (half wave plates). Such helicoidal systems exhibit optical activity; they are nearly restricted to scarab beetles (Lamellicornia) and were first described in detail by Neville \& Caveney (1969). Parker (2005) in his review Simple classical optics in animals - Reflectors and antireflectors only refers to the former type as "multilayer systems".

Multilayer colours may be superimposed by effects of structures on the cuticular surface. They can occur due to different forms of scattering at surface structures of the cuticle with a dimension of $\sim 1 \mu \mathrm{m}$ (Hinton, 1976; antireflectors in Heteroptera: Miyamoto \& Kosaku, 2002 and Lepidoptera: Yoshida, 2005), or by depressions of the surface of diameter $\sim 10 \mu \mathrm{m}$ that lead to different angles of reflected light at different parts of the depression (e.g. dimples in Cicindelids: Seago et al., 2008). The more or less planar surface of the hexagonal depression or dimple in
Cicindela produces the main contribution to the colour effect that is superimposed by the reflectance of the dimple's walls (Seago et al., 2008).

Studies on the heredity of colour morphs of carabid beetles are scarce (Puissegur, 1964; Liebherr, 1983). The complex variety of structural colour morphs of the ground beetle Poecilus lepidus (Leske) (Coleoptera: Carabidae) is genetically determined (Mossakowski et al., 2008; Paarmann et al., 2008). In the present study, we focus our interest on the remarkable difference in the appearance of the cuticular surface between males and females, which is well known for most Poecilus species (Fig. 1).

Certainly in Central European populations of P. lepidus, all males exhibit a bright elytral surface, all females a matt one, due to the virtually smooth surface in the males and micro-sculptured, knobbly one in females. At first glance, this phenomenon appears to result from secondary sexual character inheritance. However, specimens of P. lepidus from two other geographic regions differ from this pattern, females display the same bright elytral surfaces as males in the Italian Apennine Mountains (P. Brandmayr, pers. comm.) and throughout Bulgaria (B. Gueorguiev, pers. comm.). Crossbreeding experiments with German and Bulgarian specimens resulted in a dominance of matt over bright elytra in the classical Mendelian $\mathrm{F}_{2} 3: 1$ ratio, but only in females. All the males showed a bright elytral surface. These findings throw doubt on the interpretation given above, i.e. that the effect is a secondary sexual character. 




Fig. 1. Elytral surface of Poecilus lepidus. Bright colour impression of a male, and matt of a female from a German population. Elytron breadth $=2.4 \mathrm{~mm}$.
Because classical modes of inheritance do not give a sound interpretation of the data without additional assumptions, we discuss two forms of epigenetic mechanisms that might be responsible for the elytral patterns observed between males and females of this particular beetle species: (1) silencing of a gene by genomic imprinting; and (2) haplo-insufficient dominance of one allele over its counterpart. Lastly, we interpret the observed pattern by sex-limited inheritance that works when an allele (allele 1) of a gene $\mathrm{S}$ is present but does not work with another allele at the same locus (allele 2).

This paper focuses on three questions: (1) What is the difference in surface structure between bright and matt elytral cuticles? (2) How are these characters inherited? and (3) Is there any adaptive value apparent for these differences?

\section{MATERIAL AND METHODS}

\section{Material}

Specimens derived from Germany (Lueneburg Heather, leg. J. Eggers, T. Assmann) and Bulgaria (Batchevo, north of Razlog, Pirin-Macedonia, leg. H. Turin).
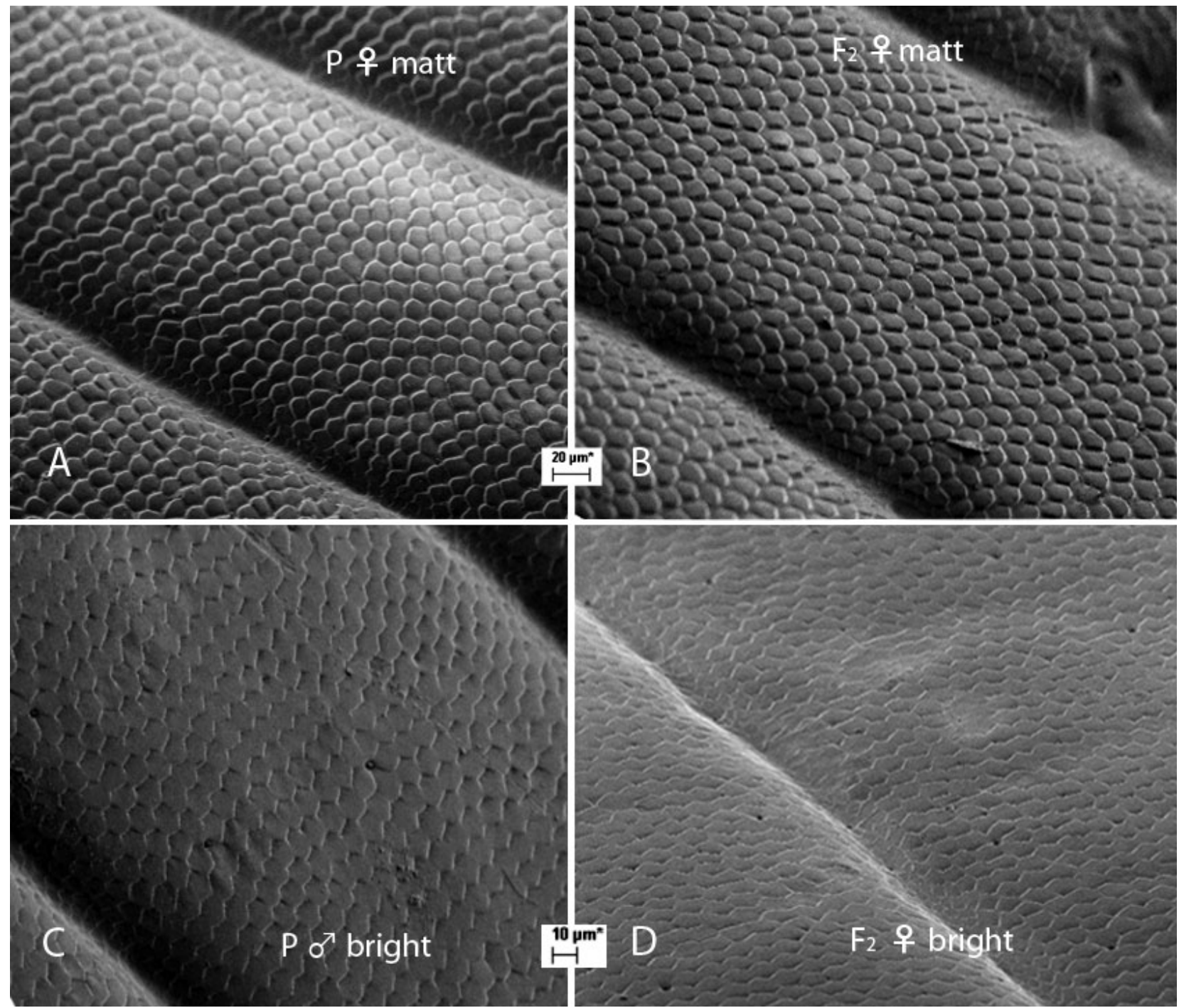

Fig. 2. Scanning electron micrographs of Poecilus lepidus elytral cuticle, dorsal view. Parental (A, C) and $\mathrm{F}_{2}(\mathrm{~B}, \mathrm{D})$ representative specimens; females display both forms in $\mathrm{F}_{2}$ : knobbly structured matt (B) and smooth (D) cuticle. 


\section{Methods}

Scanning electron microscopy (SEM) micrographs

These were produced using a ZEISS Auriga FIB/SEM (Focused Ion Beam \& Scanning microscope) at the Institute for Micro Sensors, Actuators and Systems (IMSAS), Department of Physics and Electrical Engineering, University of Bremen, Germany. Probes were not sputtered.

Crossbreeding experiments

Poecilus lepidus has one generation per year. Initially, beetles were reared for many years in order to study the life cycle of this species and later on to analyse the genetics of colour morph production. Some male specimens from Bulgaria were used in the crossing experiments performed in the present study.

\section{$\mathrm{P}$ generation}

Ten violet virgin females of the "Lüneburger Heide" strain (matt elytra) were kept without males until they reached sexual maturity. At this point, five green and sexually mature Bulgarian males were transferred to the females for a few days each (for further details of breeding conditions and crossbreeding experiments, see Paarmann et al., 2008)

\section{$\mathrm{F}_{1}$ generation}

Here, beetles were separated according to their colour in order to extend our former colour experiments with the same material, i.e. violet $(n=27)$, green $(n=25)$ and red $(n=17)$ morphs were placed into three containers. Their offspring resulted in the $\mathrm{F}_{2}$ morph numbers as shown in Table 4. Matt and bright cuticle status of females and males was recorded for each container and each generation, respectively.

Reflectance spectra were measured with a diode array spectrometer (MSC 621 II with CLH 600, ZEISS Optical Sensor Systems, Jena, Germany). The diameter of the measuring spot was about one millimetre across. Measurements were taken every four nanometres. PTFE (polytetrafluoroethylene) was used as a white standard. The reflectance curves were calculated and managed using the computer program Aspect Plus (ZEISS Optical Sensor Systems, Jena).

Photographs were taken using a Canon EOS 550D mounted on a LEITZ Photo-Macroscope. The probes were illuminated using a LED ring light (Mueller Optronic MK-S64T). Multiple pictures were combined with the programme Helicon Focus.

\section{RESULTS}

\section{Cuticle surface structure of elytra}

The surface structure of the elytra in P. lepidus is virtually smooth in males and sculptured in females. Under the assumption of Mendelian inheritance, character states should split in the $\mathrm{F}_{2}$ generation into a different number of morphs. Therefore, we tested different $\mathrm{F}_{2}$ offspring under the scanning electron microscope for intermediate states. Two morphs resulted: a smooth and a micro-sculptured one, conforming to the matt and bright forms (Fig. 2). The cell width in both males and females was $10-15 \mu \mathrm{m}$.
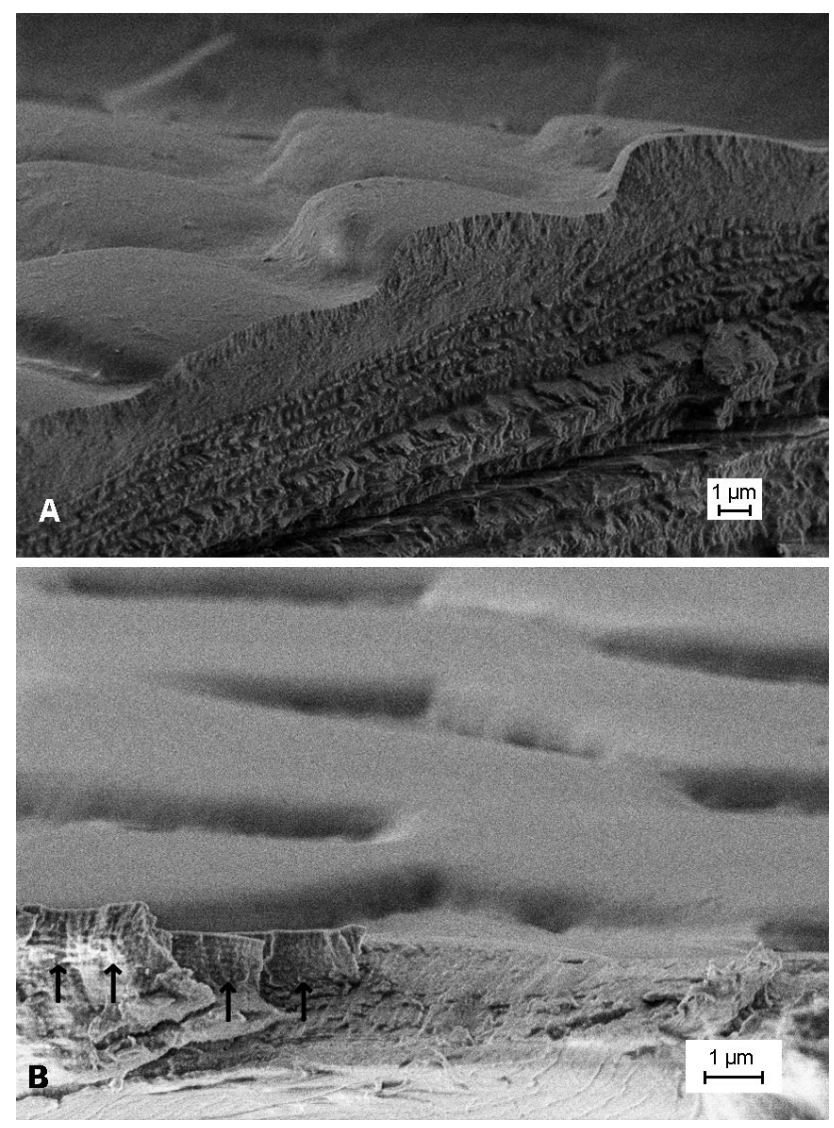

Fig. 3. Scanning electron micrographs of Poecilus lepidus elytral cuticle, $64^{\circ}$ view to the surface at the breaking edge of the scissor cut. Female (A) and male cuticle (B). A part of the multiple layers producing the structural colour are resolved in the cutting section above the arrows (B).

The impression of the microsculpture depends on the viewing angle (normal view: convex, picture turned by $180^{\circ}$ : concave); therefore, the knobbly structure was proved by looking on the probes breaking edge at an angle of $64^{\circ}$ (Fig. 3).

\section{Crossbreeding experiments}

The first crossbreeding experiment was performed with German females and Bulgarian males. All the males displayed bright elytra, all the females matt ones in the $\mathrm{F}_{1}$ generation. In the $\mathrm{F}_{2}$, a split occurred, but only in females; the matt form was dominant over the bright form in a ratio near a 3:1 ratio. All the males showed a bright elytral surface (Table 1). More details and an interpretation are given in Table 4

\section{Reflection measurements}

The reflectance of the two structural morphs differs distinctly. The maximum reflectance in the male was $28.9 \%$

TABLE 1. Conditions in natural populations of Poecilus lepidus (left and right) and in our crossbreeding experiment (middle). GER - German, BUL - Bulgarian specimens.

\begin{tabular}{|c|c|c|}
\hline$q \times \hat{0}$ & $q \times \hat{0}$ & $q \times \hat{0}$ \\
\hline $\begin{array}{c}\text { P: GER matt } \times \text { GER bright } \\
F_{1}: \text { matt bright } \\
F_{2}: \text { matt bright }\end{array}$ & $\begin{aligned} \text { P: GER matt } & \times \text { BUL bright } \\
\mathrm{F}_{1}: \text { matt } & \text { bright } \\
\mathrm{F}_{2}: \text { matt \& bright } & \text { bright }\end{aligned}$ & 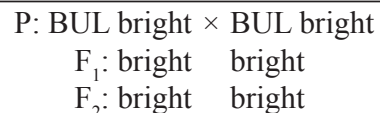 \\
\hline
\end{tabular}




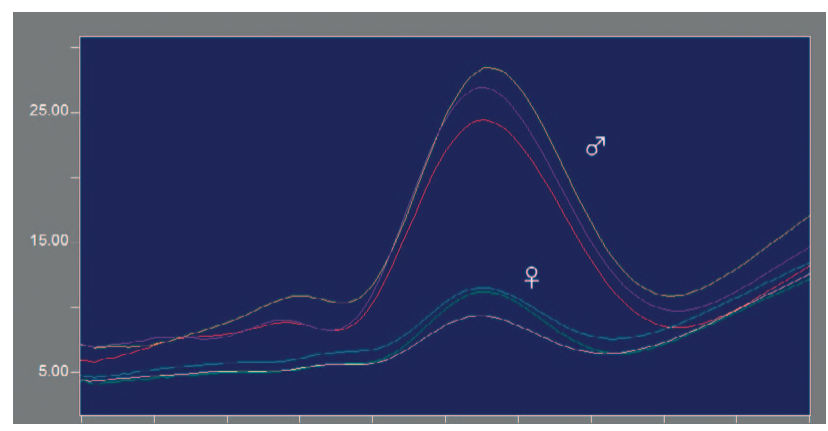

Fig. 4. Reflectance of Poecilus lepidus cuticle between a wavelength of 400 and $900 \mathrm{~nm}$. Three successive measurements of the elytral cuticle of a red male and a red female, respectively, are shown. The occurrence of different curves for the same elytron are due to changes of the probe position relevant to the light beam, which was converged to a $0^{\circ} / 0^{\circ}$ geometry.

for incident light at a wavelength of $679 \mathrm{~nm}$, whereas in the female it was $11.5 \%$ at $676 \mathrm{~nm}$ (Fig. 4). The curves showing a lower peak depend on measurements that were performed when the probe orientation was not optimally directed perpendicular to the light beam. The peak wavelength of these measurements shifted to the blue end of the spectrum, as it is typical for colours produced by a multilayer system.

\section{DISCUSSION}

\section{Cuticle surface structure of elytra}

The colours displayed by the cuticular surface of $P$. lepi$d u s$ are due to a multilayer system (Mossakowski et al., 2008) and display a bright reflection only if the cuticle surface is more or less smooth (Fig. 2). This condition was found in all male specimens examined, regardless of their geographical and genetic origin. Two morphs are present in the females: a bright and a matt one. The latter differs by a sculptured surface structure of the elytra (Fig. 2).

In beetles, a similar but inverse situation was found in tiger beetles of the genus Cicindela. The cuticle surface of $C$. campestris L. is covered by depressions with a diameter of about 8-10 $\mu \mathrm{m}$ (Mossakowski, 1979). These grooves occur on an undulating surface, additionally covered by larger tubercles (Stegmann, 1930). Such structures were also found in many other species (e.g. Schultz, 1983; Schultz \& Rankin, 1985). Thus, the colour reflectance is a mixture of the colour of the plain bottom area of the depressions as well as that differing in wavelength due to the different angles of the walls (Seago et al., 2008). These authors referred to such depressions as "dimples".

The cuticle surface of matt $P$. lepidus is sculptured but the effect of the uneven structure of these humps causes the same effect as the dimples in Cicindela spp.

\section{Inheritance}

We considered a number of modes of inheritance that are associated with a sex-dependent distribution of traits in the offspring (Table 2). None of these hypotheses can unambiguously explain the results of our crossbreeding experiments or the situation in the field. Infections by the endosymbiotic bacteria Wolbachia are also known to influence the result of crossbreeding experiments. But we had a high breeding success with our beetles and a normal sex ratio of about $1: 1$ in the offspring generations.

In consequence, we will discuss three concepts, two epigenetic ones: (i) silencing of a gene by genomic imprinting; (ii) haplo-insufficient dominance of one allele over its counterpart; and (iii) sex-limited inheritance and its dependence on the geographic distribution of a specific allele.

\section{Genomic imprinting}

Although genomic imprinting has been described mainly in plants and mammals, the term was first used in a study on an insect, the fungus gnat, Sciara (Diptera: Sciaridae) (Crouse, 1960). Epigenetic regulation of gene expression is widespread, as is known from cell or tissue specific gene activity. In imprinting, one of the two alleles at a gene locus is silenced by some molecular process, such as DNAmethylation. As an example, mammalian development can be mentioned: one of the two X-chromosomes is widely silenced at an early level of female development by genomic imprinting (Vigé et el., 2008).

The number of imprinted genes in Drosophila is currently under discussion but it is evident that in this insect only a few imprinted genes are known which have an effect on the adult phenotype (Coolon et al., 2012). At first sight this concept may fit our results. As stated by Lloyd (2000, p. 35), "This silencing effect depends only on the sex of the parent, not on the sex of the offspring, and thus it is reset every generation".

An interpretation using one gene with two alleles, which differ between the regions, does not work. Therefore, we have introduced a second gene in our interpretation with the assumption that its alleles are present in all popula-

TABLE 2. Modes of inheritance tested to interpret the crossbreeding results for Poecilus lepidus.

\begin{tabular}{ll}
\hline Model & Counter-argument \\
\hline Mendelian & No uniformity in $\mathrm{F}_{1}$; split in $\mathrm{F}_{2}$ depends on gender. \\
Sex chromosome linked & Males do not display different phenotypes; $3: 1$ in $\mathrm{F}_{2}$ females. \\
Attached $\mathrm{X}$ chromosome & Needs only 2 sex-linked phenotypes, because the other two are not viable. Our breeding success is $>90 \%$. \\
Maternal & Does not conform because of $3: 1$ split in $\mathrm{F}_{2}$. \\
Parent-of-origin & bes not conform because of $3: 1$ split in $\mathrm{F}_{2}$. \\
\hline Genomic imprinting & Deeds additional assumptions. See discussion. \\
Haplo-insufficient dominance & Needs additional assumptions. See discussion. \\
Sex-limited & Geographic differences. See discussion.
\end{tabular}

$\mathrm{F}_{1}, \mathrm{~F}_{2}$ refer to crossbreeding German $\times$ Bulgarian Poecilus lepidus. ${ }^{\mathrm{a}}$ Based on females with two $\mathrm{X}$ chromosomes fused at the centromere and usually a $\mathrm{Y}$ chromosome. ${ }^{\mathrm{b}}$ The phenotypic effect of an allele depends on whether it is inherited from the mother or the father. 
TABLE 3. Interpretation of crossbreeding German $\times$ Bulgarian Poecilus lepidus under the assumption of haplo-insufficient dominance inheritance. A sound explanation is only possible when the gene is assumed to be on an autosome and one of the alleles in males, $\mathrm{S} 1$ or S2, is suppressed or inherited sex-limited (bold-marked allele). Numbers in the right column indicate protein units encoded by the gene (see Discussion).

\begin{tabular}{|c|c|c|}
\hline 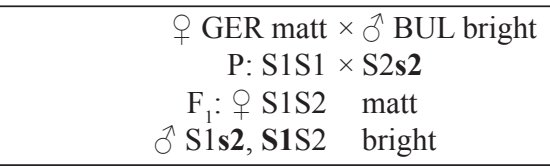 & $\begin{array}{l}\text { P } 1 \mathrm{~S} 1 \\
\mathrm{~S} 1 \mathrm{~S} 2 \\
\mathrm{~S} 2 \mathrm{~S} 1 \\
\mathrm{~S} 2 \mathrm{~S} 2\end{array}$ & $\begin{array}{l}24 \text { matt } \\
20 \text { matt } \\
20 \text { matt } \\
16 \text { bright }\end{array}$ \\
\hline 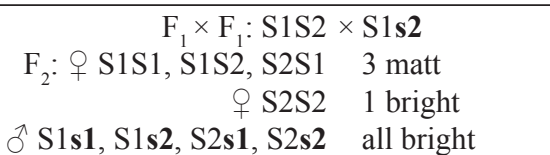 & $\begin{array}{r}\text { O S1s1 } \\
\text { S1s2 } \\
\text { S2s2 } \\
\text { Thresho }\end{array}$ & $\begin{array}{l}12 \text { bright } \\
12 \text { bright } \\
8 \text { bright } \\
18\end{array}$ \\
\hline
\end{tabular}

tions and always produce the matt form of elytra. If the first gene is autosomal, only one of the two alleles at the locus will be silenced, whilst the other should produce matt males. Such males have so far not been found to occur in nature nor also in our experiments. This problem may be resolved if it is supposed that the gene governing the elytral traits is on the sex chromosome. P. lepidus has an XX/XO sex determining chromosomal system (Nettmann, 1986; Serrano \& Galian, 1998). Hence, the offspring should show a ratio of $1: 1$ in females in the $\mathrm{F}_{2}$ generation (matt: bright), instead of our experimental result of $3: 1$. As a consequence, we cannot present a sound interpretation based solely on genomic imprinting.

\section{Haplo-insufficient dominance}

This form of incomplete dominance exists if the expression of one copy of a gene at a particular locus is insufficient to produce the coded protein. It could work under the assumption that the two alleles produce a different amount of units in terms of their gene products and a threshold must be overcome to induce the next step in protein production.

When we specify that allele S1 produces 12 and S2 produces 8 units and that at least 18 units are necessary to produce the gene product that changes bright to matt, we get the result that $\mathrm{S} 1$ is haplo-insufficient dominant to $\mathrm{S} 2$ under two assumptions: the gene $\mathrm{S}$ is positioned on an autosome and the expression of one allele is suppressed in males (Table 3).

How frequently does this mode occur in animals, in particular in insects? Wilkie (1994) states that "Haplo-insufficient loci are relatively unusual: a careful survey of the Drosophila genome showed only 56 loci associated with an altered phenotype when present as a single copy, ...". In Drosophila 19,684 genes are known (UniProt, 2014). Therefore, this mode alone also fails to provide a convincing interpretation of the present findings.

\section{Sex-limited inheritance}

Sex-limited inheritance fits the data when the differences in females from northern and southern populations is interpreted as being due to a dimorphism that is under the control of an autosomal gene. If a trait has a sex-limited expression this phenomenon will normally occur within a population. The consequence is that selection can only affect the sex with the sex-limited trait; in the other sex the gene is hidden to selection. Such a scenario may well have significant impacts on selection (Reinhold, 1999). In contrast, the matt and the bright females of $P$. lepidus occur in different geographical regions. We have a sex-limited trait in northern populations (bright males; matt females), uniformity in southern populations, and a dimorphism in females only in our crossbreeding experiments between German and Bulgarian specimens (Table 4). All attempts to interpret the data lead to an autosomal gene. Such a conclusion is concordant with the statement that autosomal genes are involved in traits limited to the homogametic sex, in the case of P. lepidus, the female sex (Reinhold, 1999).

\section{Adaptation}

Several effects of bright versus matt cuticular surface may play a role in adaptation, such as camouflage, temperature modulation, or adhesion during copula.

The reflectance measurements show the expected differences. Bright males of the same colour reflect more light than matt females. In consequence, it may be hypothesised that females will increase their temperature more quickly and to a higher value than males under identical solar radiation. Because the difference is lower than 10\% (Table 5 ), the temperature effect on the elytra will be small.

Considering egg maturation in more northern regions, this difference may itself be interpreted as an adaptation. The bright female morph occurs in the southernmost area of the species range in Italy, the Apennine Mountains. All Bulgarian females in the Museum of Sofia belong also to

TABLE 4. Interpretation of crossbreeding experiments with German (GER) and Bulgarian (BUL) Poecilus lepidus compared with the assumed situation in the natural populations. Numbers of offspring are indicated in brackets. In $\mathrm{F}_{2}$ matt is dominant to bright; phenotype matt is suppressed in males.

\begin{tabular}{|c|c|c|}
\hline GER $\phi \times$ GER $\hat{\sigma}$ & GER $\phi \times$ BUL $\hat{~}$ & $\mathrm{BUL} \rho \times \mathrm{BUL} \hat{\sigma}$ \\
\hline P: S1S1 matt $\times$ S1S1 bright & P: S1S1 matt $\times$ S2S2 bright & P: S2S2 bright $\times$ S1S1 bright \\
\hline $\mathrm{F}_{1}: \mathrm{S} 1 \mathrm{~S} 1 \mathrm{matt} \mathrm{S} 1 \mathrm{~S} 1 \mathrm{bright}$ & $\mathrm{F}_{1}: \mathrm{S} 1 \mathrm{~S} 2$ matt (30) $\mathrm{S} 1 \mathrm{~S} 2$ bright (40) & $\mathrm{F}_{1}: \mathrm{S} 2 \mathrm{~S} 2$ bright $\mathrm{S} 1 \mathrm{~S} 1 \mathrm{bright}$ \\
\hline $\mathrm{F}_{2}: \mathrm{S} 1 \mathrm{~S} 1 \mathrm{matt}$ & $\begin{aligned} \mathrm{F}_{2}: \mathrm{S} 1 \mathrm{~S} 1,2 \mathrm{~S} 1 \mathrm{~S} 2 \text { matt }(50) & \text { S1S1, 2 S1S2 } \\
\text { S2S2 bright }(12) & \text { S2S2 bright }(\Sigma 83)\end{aligned}$ & $\mathrm{F}_{2}: \mathrm{S} 2 \mathrm{~S} 2$ bright $\mathrm{S} 1 \mathrm{~S} 1 \mathrm{bright}$ \\
\hline
\end{tabular}


TABLE 5. Incident radiation [at $680 \mathrm{~nm}=55 \mathrm{~W} / \mathrm{m}^{2}$ (Schulze, 1970)] and proportion reflected by the elytra of Poecilus lepidus.

\begin{tabular}{lccc}
\hline & Reflectance & \multicolumn{2}{c}{ Radiation } \\
\cline { 3 - 4 } & maximum $\%$ & reflected $\mathrm{W} / \mathrm{m}^{2}$ & absorbed \% \\
\hline Male & 28.9 & 16.9 & 83.1 \\
Female & 11.5 & 6.4 & 93.6 \\
\hline
\end{tabular}

this morph, the southernmost edge of the species range on the Balkan Peninsula.

In general, the females of the genus Poecilus show matt elytral surfaces, but $P$. lepidus is the only species with such a geographical variability in this particular feature. Schultz \& Hadley (1987) failed to find any significant temperature differences between isolated elytra of specimens of the same Cicindela species with either black or coloured elytra (compare also Hadley et al., 1992). Only specimens with white cuticles displayed a difference. All these cicindelids have a surface structure comparable to the dimples described above and their inner structure is the same, a multilayer system. But white in Cicindela depends on a quite different internal structure (Schultz, 1983). In P. lepi$d u s$, the surface structures differ between smooth in bright and sculptured in matt cuticles. If the matt structure of the cuticle has a mimetic effect or has an effect on copulation, the question arises "Why are such clear geographic differences found?"

\section{CONCLUSION}

\section{Structure}

We found two structural morphs for the elytral surface, which produce the different impressions of brightness to the human eye.

\section{Inheritance}

We cannot interpret the data on the basis of genomic imprinting alone, because every new approach produced new obstacles. An interpretation by insufficient haplo-dominance needs two assumptions: the hypothesised gene must be on an autosome and one of the alleles must be silenced in males. The gene cannot be located on the X chromosome because under this assumption, the $\mathrm{F}_{2}$ offspring ratio in females should be $1: 1$.

An interpretation by sex-limited inheritance fits the situation in northern populations (bright males, matt females). The uniform southern most populations must have different alleles; therefore, the observed pattern may be interpreted by sex-limited inheritance that depends on the presence or absence of a particular allele.

\section{Adaptation}

The measurements gave a remarkable difference between matt and bright cuticle reflectance. As a consequence of this difference, a matt cuticle of the same colour under identical radiation input may warm up to a higher temperature, due to structural differences of the cuticle surface, which may in turn have adaptive survival advantages to insects living in cooler climes.
ACKNOWLEDGEMENTS. We would like to express our cordial thanks to: H. Turin, J. Eggers and T. Assmann for providing specimens of P. lepidus; E.-M. Meyer, Department Physics / Electrical Engineering, Institute for Microsensors, Actuators and Systems (IMSAS), University of Bremen for performing the SEM photos; M. Patzwald and E. Michaelis, Zeiss Optical Sensor Systems, Jena, for their kind help in the measurement of reflectance; P. Brandmayr for providing information on the bright females of P. lepidus from the Apennine populations; B. Guéorguiev for his examination of Bulgarian material of $P$. lepidus ( $>50$ males, 34 females; collection of the National Museum of Natural History, Sofia); J. Serrano and H. Nettmann for helpful discussions, S. Venn for polishing our English in a former draft, two reviewers for their helpful comments, and last but not least, H. Loxdale for his editorial improvements to the MS.

\section{REFERENCES}

Coolon J.D., Stevenson K.R., McManus C.J., Graveley B.R. \& WitткорP P.J. 2012: Genomic imprinting absent in Drosophila melanogaster adult females. - Cell Report 2: 69-75.

Crouse H.V. 1960: The controlling element in sex chromosome behaviour in Sciara. - Genetics 45: 1429-1443.

Hadley N.F., Savill A. \& Schultz T.D. 1992: Coloration and its thermal consequences in the New Zealand tiger beetle Neocicindela perhispida. - J. Therm. Biol. 17: 55-61.

HinTON H.E. 1976: Recent work on physical colours of insect cuticle. In Hepburn H.R. (ed.): The Insect Integument. Elsevier, Amsterdam, pp. 475-496.

LieBHERR J.K. 1983: The genetic basis for polymorphism in the ground beetle Agonum decorum (Coleoptera: Carabidae). Ann. Entomol. Soc. Am. 76: 349-358.

Lloyd V. 2000: Parental imprinting in Drosophila. - Genetica 109: 35-44.

Miyamoto K. \& Kosaku A. 2002: Cuticular microstructures and their relationship to structural color in the shieldbug Poecilocoris lewisi Distant. - Forma 17: 155-167.

Mossakowski D. 1979: Reflection measurements used in the analysis of structural colours of beetles. $-J$. Microsc. 116: 351-364.

Mossakowski D., Paarmann W., Rohe W., Lüchtrath I. \& AssMANN T. 2008: Multilayer structural colours in Poecilus lepidus (Coleoptera, Carabidae). In Penev L., Erwin T. \& Assmann T. (eds): Back to the Roots and Back to the Future. Towards a New Synthesis amongst Taxonomic, Ecological and Biogeographical Approaches in Carabidology. Pensoft, Sofia, Moscow, pp. 173-182.

Nettmann H.-K. 1986: Karyotyp und Stammesgeschichte der Carabiden. PhD Thesis, Bremen University, 170 pp.

Neville A.C. \& CaVeney S. 1969: Scarabaeid beetle exocuticle as an optical analogue of cholesteric liquid crystals. - Biol. Rev. 44: 531-562.

Paarmann W., Assmann T., Rohe W., Lüchtrath I. \& MossaKowski D. 2008: Heredity of the elytral colour in adults of Poecilus lepidus Leske (Col., Carabidae). In Penev L., Erwin T. \& Assmann T. (eds): Back to the Roots and Back to the Future. Towards a New Synthesis amongst Taxonomical, Ecological and Biogeographical Approaches in Carabidology. Pensoft, Sofia, Moscow, pp.183-194.

PARKER A.R. 2005: Simple classical optics in animals - Reflectors and antireflectors. In Kinoshita S. \& Yoshioka S. (eds): Structural Colors in Biological Systems - Principles and Applications. Osaka University Press, Osaka, pp. 29-52.

Puissegur C. 1964: Recherches sur la génétique des Carabes. Vie et Milieu (Suppl.) 18: 1-288. 
REINHOLD K. 1999: Evolutionary genetics of sex-limited traits under fluctuating selection. - J. Evol. Biol. 12: 897-902.

Schultz T.D. 1983: The ultrastructure, Physiology, and Ecology of the Epicuticular Interference Reflectors of Tiger Beetles (Cicindela). Ph.D. Thesis, University of Texas, Austin, 214 pp.

Schultz T.D. \& HadLey N.F. 1987: Structural colors of tiger beetles and their role in heat transfer through the integument. Physiol. Zool. 60: 737-745.

Schultz T.D. \& Rankin M.A. 1985: The ultrastructure of the epicuticular interference reflectors of tiger beetles (Cicindela). J. Exp. Biol. 117: 87-110.

Schulze R.W. 1970: Strahlenklima der Erde. Steinkopf, Darmstadt, $220 \mathrm{pp}$.

Seago A.E., Brady P., Vigneron J.-P. \& Schultz T.D. 2008: Gold bugs and beyond: a review of iridescence and structural colour mechanisms in beetles (Coleoptera). - J. R. Soc. Interface 6: $165-184$.

SERrano J. \& Galian J. 1998: A review of karyotypic evolution and phylogeny of carabid beetles (Coleoptera). In Ball G., Casale A. \& Vigna Taglianti A. (eds): Phylogeny and Classification of Caraboidea. Phylogeny and Classification of Cara- boidea (Coleoptera: Adephaga). Proceedings of a Symposium (28 August, 1996, Florence, Italy). XX International Congress of Entomology. Museo Regionale di Scienze Naturali, Torino, pp. 191-228.

Stegmann F. 1930: Die Flügeldecken der Cicindelidae. Ein Beitrag zur Kenntnis der Insektencuticula. - Z. Morph. Oekol. Tiere 18: 1-73.

UniProt 2014: The UniProt Consortium. Activities at the Universal Protein Resource (UniProt). Nucl. Acids Res. 42: D191D198.

Vigé A., Gallou-Kabani C. \& Junien C. 2008: Sexual dimorphism in non-Mendelian inheritance. - Pediat. Res. 63: 340347.

WILKIE A.M. 1994: The molecular basis of genetic dominance. J. Med. Genet. 31: 89-98.

Yoshida A. 2005: Antireflective microstructures on the wings of butterflies and moths. In Kinoshita S. \& Yoshioka S. (eds): Structural Colors in Biological Systems. Principles and Applications. Osaka University Press, Osaka, pp. 249-264.

Received December 16, 2013; revised and accepted May 12, 2014 Prepublished online October 1, 2014 